\title{
Impaired Surface Membrane Expression of C3bi but Not C3b Receptors on Neonatal Neutrophils
}

\author{
MARGARET C. BRUCE, JILL E. BALEY, KATHLEEN A. MEDVIK, AND MELVIN BERGER \\ Pulmonary [M.C.B.], Neonatology [J.E.B., K.A.M.], and Immunology [M.B.] Divisions, Department of \\ Pediatrics, Case Western Reserve Medical School, Cleveland, Ohio 44106
}

\begin{abstract}
Because increased complement receptor expression is necessary for optimal function of adult neutrophils, we tested the hypothesis that the increased susceptibility of neonates to infection might be due to an impaired ability of neonatal neutrophils to increase expression of complement receptors in response to chemotactic stimuli. We used monoclonal antibodies and flow cytometry to compare surface expression of the receptors for the complement components C3b (CR1) and C3bi (CR3) on adult and neonatal cord blood neutrophils (PMNs). We also compared receptor expression on PMNs from infants delivered by cesarean section without labor versus infants delivered vaginally. Expression of both CR1 and CR3 was minimal on resting adult and neonatal PMNs maintained at $0^{\circ} \mathrm{C}$. There was a modest increase in expression of both receptors when $\mathrm{PMNs}$ were warmed to $37^{\circ} \mathrm{C}$. This increase was similar on adult and neonatal cells, both unfractionated in whole blood and after isolation with Percoll density centrifugation, with one exception. Expression of CR1 was greater on isolated PMNs from vaginally delivered infants versus adults when the cells were warmed to $37^{\circ} \mathrm{C}$. This difference was not observed with cells from infants delivered by cesarean section without labor, suggesting this modest increase in receptor expression may be due to factors associated with labor. When isolated cells were stimulated with either $\mathbf{N}$-formyl-methionyl-leucyl-phenylalanine or zymosan-activated serum, expression of CR1 increased to the same extent in both neonatal and adult PMNs. In contrast, maximal $\mathrm{CR} 3$ expression on cord PMNs stimulated with N-formyl-methionyl-leucyl-phenylalanine or zymosan-activated serum was only $75 \%$ of the adult values. This was significantly less than CR3 expression in adult PMNs across a broad range of $\mathbf{N}$-formylmethionyl-leucyl-phenylalanine concentrations. Maximal stimulated expression of both receptors was the same in PMNs from infants delivered by cesarean section without labor and from infants delivered vaginally. The diminished CR3 expression on cord PMNs was not due to decreased responsiveness to $\mathbf{N}$-formyl-methionyl-leucyl-phenylalanine per se since deficient CR3 expression was observed at all concentrations tested and also when zymosan-activated serum was the stimulus. Our observations of impaired expression of CR3, which is necessary for adherence and directed migration, may explain some of the impairment of these functions in neonatal neutrophils. (Pediatr Res 21: 306-311, 1987)
\end{abstract}

Received July 15, 1986; accepted October 29, 1986.

Correspondence Dr. Margaret Bruce, Department of Pediatrics, Pulmonary Division, Case Western Reserve Medical School, 2101 Adelbert Road, Cleveland, $\mathrm{OH} 44106$.

This work was supported by National Institute of Health Grant HL 31172 and by the Children's Research Fund of Cleveland.

\author{
Abbreviations \\ PMN, polymorphonuclear cells \\ f-MLP, N-formyl-methionyl-leucyl-phenylalanine \\ HBSS, Hanks' balanced salt solution \\ FITC, fluorescein-isothiocyanate \\ PMSF, phenylmethyl-sulfonyl fluoride \\ CR1, type 1 complement receptor, $\mathrm{C} 4 \mathrm{~b} / \mathrm{C} 3 \mathrm{~b}$ receptor \\ CR3, type 3 complement receptor, $\mathrm{C} 3$ bi receptor
}

The increased susceptibility of the newborn infant to infection suggests that there might be a deficiency in the ability of the PMN to phagocytize and kill microorganisms (1). Numerous studies have compared the functional capabilities of PMNs obtained from neonates with those obtained from adults in an effort to identify and characterize the defect(s) in the neonatal PMNs. Cord and adult PMNs were shown to be similar with respect to the binding kinetics of the synthetic chemoattractant f-MLP, e.g. the saturation of f-MLP binding sites and the dissociation of bound ligand $(2,3)$. Similarly, the resting level of superoxide production, as well as the ability to increase superoxide production in response to stimuli, have been found to be comparable in the PMNs of adults and newborns (4).

In contrast, when stimulated with f-MLP, neonatal PMNs have been found to be impaired relative to adult PMNs with respect to adherence, redistribution of adherence sites, uropod formation, and directed migration (2). The normal increase in intracellular free calcium concentration that occurs upon stimulation of adult PMNs with f-MLP is also reduced in newborns' PMNs. (3). In addition, phagocytosis by neonatal cells has been shown to be deficient when limiting amounts of serum were used for opsonization of the test organisms $(5,6)$. This suggests that neonatal PMNs may require increased amounts of complement to promote a given level of attachment and/or ingestion. Thus, the observed abnormalities in adherence and directed migration may delay the response of the neonatal PMN to infection, and a limited concentration of opsonins at the site of infection may impair phagocytosis. Both of these phenomena are likely to contribute to the increased susceptibility of the newborn to infection (1).

Recent studies from our own and other laboratories have shown that chemoattractants and other stimuli cause increases in the surface expression of membrane receptors for the major opsonically active fragments of the serum complement system, C3b (CR1) and C3bi (CR3) $(7,8)$. Both the C3b (CR1) and C3bi (CR3) receptors of normal adult neutrophils are present in intracellular pools and are rapidly translocated to the surface membrane when the cells are activated (7-11). The increased surface expression of CR1 is believed to be necessary for optimal phagocytosis while increased CR 3 expression is necessary for cell adherence and attachment in addition to phagocytosis $(11,16-$ 20). 
The present investigations were carried out to test the hypothesis that neonatal neutrophils might be deficient with respect to their ability to increase the surface expression of these complement receptors in response to stimulation. We compared the responses of adult and cord blood neutrophils to the synthetic chemoattractant f-MLP and to zymosan-activated serum, which serves as a source of C5a des-Arg, a more physiologic stimulus. CR1 and CR3 expression were quantitated using monoclonal antibodies and flow cytometry. In addition, we examined the effect of type of delivery (vaginal versus cesarean section) on receptor expression in isolated cord blood PMNs.

\section{MATERIALS AND METHODS}

Patient population. Venous blood $(20-30 \mathrm{ml})$ was drawn from the umbilical vessels of placentas of normal, full-term infants within 5-10 min of either vaginal delivery or cesarean section without labor. Epidural anesthetics (bupivacaine/epinephrine with or without chloroprocaine) were administered to all of the mothers with the exception of one mother who was treated with a local anesthetic (lidocaine). We excluded blood samples from the placentas of mothers with a history of gestational or adult onset diabetes mellitus, chronic hypertension, pregnancy-associated hypertension, or those cases in which a cesarean section was preceded by labor. Equivalent samples of peripheral venous blood were obtained from normal adult donors and processed simultaneously with cord samples as pairs. Blood was anticoagulated with heparin at a final concentration of $20 \mathrm{U} / \mathrm{ml}$.

Isolation and incubation of PMNs. PMNs were isolated using a modification of the method of Harbeck et al. (12) as previously described (7). Briefly, PMNs were isolated using density gradients of Percoll (Pharmacia Fine Chemicals, Piscataway, NJ) made isotonic with phosphate-buffered saline, $\mathrm{pH} 7.4$. In order to separate erythrocytes from cord PMNs, it was necessary to centrifuge the Percoll density gradient for $22 \mathrm{~min}$ instead of $17 \mathrm{~min}$ as described by Berger et al. (7). Contaminating erythrocytes were removed by hypotonic lysis and isolated PMNs were washed twice in HBSS without calcium, magnesium, or phenol red (HBSS-w/o). PMNs were then resuspended in this solution containing $0.1 \%$ gelatin at a concentration of $10^{6} / \mathrm{ml}$ and incubated at $37^{\circ} \mathrm{C}$ in buffer alone or with chemoattractants for $1 \mathrm{~h}$ to assure complete activation. In some experiments, whole blood (both adult and cord) was incubated at $37^{\circ} \mathrm{C}$ for $1 \mathrm{~h}$ with or without chemoattractant and reacted with monoclonal antibodies before further processing. Erythrocytes were then removed by hypotonic lysis. The leukocytes were washed in HBSS and stained with FITC conjugate and prepared for cytometry as described for isolated PMN below. All washes were performed by centrifugation at $200 \times g$ for $10 \mathrm{~min}$ at $4^{\circ} \mathrm{C}$.

f-MLP was obtained from Peninsula Laboratories, Belmont, $\mathrm{CA}$, diluted in dimethyl sulfoxide to a concentration of $10^{-3} \mathrm{M}$ and stored at $-70^{\circ} \mathrm{C}$. PMSF was purchased from Sigma Chemical Co., St. Louis, MO. Serum was activated with zymosan (13). Monoclonal antibody to the human $\mathrm{C} 3 \mathrm{~b}$ receptor (CR1), prepared by immunizing BALB/c mice with purified CRI protein from human erythrocytes (10), was the generous gift of Dr. John O'Shea, National Institutes of Health, Bethesda, MD. Monoclonal antibody (M1/70) to the Mac 1 antigen on the C3bi receptor (CR3) (14) was also provided by Dr. O'Shea. FITC-conjugated $\mathrm{F}\left(\mathrm{ab}^{\prime}\right)_{2}$ fragments of goat antimouse IgG were obtained from Cappel Laboratories (Cochranville, PA).

Antibody staining. After incubation with the chemoattractants f-MLP or zymosan-activated serum, neutrophils were washed with ice-cold HBSS containing $0.1 \%$ bovine serum albumin, $0.05 \% \mathrm{NaN}_{3}$ to prevent antibody capping, and $10^{-4} \mathrm{M}$ PMSF to inhibit proteolysis of complement receptors (HBSS+) and resuspended in $50 \mu \mathrm{l}$ of this medium. Saturating amounts of monoclonal antibodies to either CR1 or CR3 were then added in a volume of $50 \mu \mathrm{l}$ in HBSS+ as reported previously (7). The neutrophils were incubated with the antibodies for $30 \mathrm{~min}$ at $4^{\circ}$
$\mathrm{C}$ on a rotator and then washed twice with cold HBSS+. The PMNs were then resuspended in $50 \mu \mathrm{l}$ of HBSS+ and incubated with excess FITC conjugated $\mathrm{F}\left(\mathrm{ab}^{\prime}\right)_{2}$ fragments of anti-mouse IgG for $30 \mathrm{~min}$ at $4^{\circ} \mathrm{C}$. The cells were washed twice in HBSS+ then an additional wash was performed using phosphate-buffered saline containing $0.05 \% \mathrm{NaN}_{3}$. The cells were then resuspended in this solution and kept on ice until examination in the flow cytometer, generally within $1 \mathrm{~h}$ after the final wash. No fixatives were used.

Quantitation of cell fluorescence and volume was performed using a FACS Analyzer (Becton-Dickinson and Co., Mountain View, CA) standardized with $7.8 \mu \mathrm{m}$-diameter fluorescent microbeads as described previously (7). The PMNs in mixed leukocyte preparations were identified for analysis based on their characteristic right angle light scattering properties which are indicative of their granule content, and volume. Data from 10,000 PMN were collected for each sample. Fluorescence was determined using logarithmic amplification. Both adult and cord PMNs behaved as single symmetric populations with uniform staining as illustrated previously (7), hence relative fluorescence values were converted to their linear equivalents by the Consort 30 computer in order to facilitate comparisons between samples by their arithmetic means. Background fluorescence was determined by staining cells with the same FITC conjugates but without antireceptor antibodies. This has previously been shown to be the equivalent of using nonimmune monoclonal control antibodies (12). These values were then subtracted from all other results.

Statistical analysis of data. Values presented represent the mean of each population \pm 1 SEM. The significance of differences between groups was determined by using Student's $t$ test for unpaired values. The $p$ values reported are for a two-tailed $t$ test; $p$ values $<0.05$ were considered significantly different. Bonferroni's correction was applied to analyses involving multiple $t$ tests (15).

\section{RESULTS}

Evaluation of the effect of Percoll density gradient isolation procedure on receptor expression by PMNs. Previous studies indicated that neutrophils isolated by Percoll density gradients or other procedures involving centrifugation underwent a spontaneous increase in receptor expression when they were warmed to $37^{\circ} \mathrm{C}(7,8)$. Initially we studied receptor expression on cells in whole blood not subjected to the isolation procedure to compare the response of adult and neonatal PMNs. In these experiments six unfractionated blood samples from adult donors and five cord blood samples from infants delivered by cesarean section were maintained at 0 or $37^{\circ} \mathrm{C}$ for $1 \mathrm{~h}$ with or without $\mathrm{f}$ MLP, centrifuged for $10 \mathrm{~min}$ at $4^{\circ} \mathrm{C}$, and stained with anti-CR 1 or anti-CR3 and with FITC conjugates. Red cells were then removed by hypotonic lysis and the cell pellets prepared for fluorescence determination. Neutrophils in mixed leukocyte preparations were distinguished by volume and right angle light scatter gating as described above. Comparison of staining in the two groups at 0 and at $37^{\circ} \mathrm{C}$ with or without $\mathrm{f}-\mathrm{MLP}$ indicated that there was no difference in fluorescence of CR1 between adult and cord cells under any of these conditions. (Table 1) The fluorescence of CR3 on cord blood cells at $37^{\circ} \mathrm{C}$ was $75 \%$ of adult values although the two groups were not significantly different. Stimulation with f-MLP increased CR3 expression on both the cord and adult cells but CR3 expression on the cord cells was significantly lower, reaching only $62 \%$ of the adult values $(p=0.003)$.

Next we compared the effects of the Percoll density gradient isolation procedure on the temperature-dependent increase in expression of PMN receptors on adult versus neonatal (cesarean and vaginal delivery) cells (Table 2). We found it necessary to centrifuge the neonatal blood cells for a slightly longer period of time, $22 \mathrm{~min}$ as opposed to $17 \mathrm{~min}$ which had previously been 
BRUCE $E T A L$.

Table 1. Effects of temperature and f-MLP on receptor expression on adult versus cord PMNs in whole blood*

\begin{tabular}{cccccccc}
\hline & \multicolumn{3}{c}{ CR1 } & & \multicolumn{3}{c}{ CR3 } \\
\cline { 2 - 4 } \cline { 6 - 8 } & $0^{\circ}$ & $37^{\circ}$ & f-MLP $\dagger$ & & $0^{\circ}$ & $37^{\circ}$ & f-MLP $\dagger$ \\
\hline Adult & $1.75 \pm 0.57$ & $4.78 \pm 0.67 \ddagger$ & $10.88 \pm 1.41$ & & $2.81 \pm 0.65$ & $8.69 \pm 0.84 \ddagger$ & $23.02 \pm 1.73 \S$ \\
Cord & $2.70 \pm 0.65$ & $4.69 \pm 1.28$ & $10.96 \pm 2.19$ & & $3.07 \pm 0.44$ & $6.52 \pm 1.66$ & $14.26 \pm 2.54$ \\
\hline
\end{tabular}

* Results represent the mean fluorescence \pm 1 SEM.

$\dagger$ The concentration of $\mathrm{f}-\mathrm{MLP}$ was $10^{-6} \mathrm{M}$, PMNs were incubated at $37^{\circ} \mathrm{C}$.

$\ddagger$ Although both CR1 and CR3 expression increased in buffer alone at $37^{\circ} \mathrm{C}$ compared to $0^{\circ} \mathrm{C}$ as reported previously $(7,8)$, there were no significant differences between cord and adult cells.

$\S$ Expression of CR3 receptor was greater on adult than on cord PMNs ( $p=0.003$; corrected for multiple t-tests).

Table 2. Effect of percoll isolation on temperature-dependent receptor expression*

\begin{tabular}{llrrrr}
\hline & \multicolumn{3}{c}{ CR1 } & \multicolumn{2}{c}{ CR3 } \\
\cline { 2 - 3 } \cline { 5 - 6 } & \multicolumn{1}{c}{$0^{\circ}$} & \multicolumn{1}{c}{$0^{\circ}$} & \multicolumn{1}{c}{$37^{\circ}$} \\
\hline Adult $(n=6)$ & $1.00 \pm 0.19$ & $5.97 \pm 0.61$ & $2.43 \pm 0.80$ & $10.44 \pm 0.62$ \\
Cesarean section $(n=6)$ & $2.36 \pm 0.6$ & $8.34 \pm 1.16$ & $2.76 \pm 0.87$ & $8.90 \pm 0.98$ \\
Adult $(n=4)$ & $2.29 \pm 1.0$ & $5.84 \pm 0.21$ & $2.56 \pm 0.60$ & $10.30 \pm 0.59$ \\
Vaginal $(n=4)$ & $1.85 \pm 0.59$ & $10.06 \pm 1.02 \dagger$ & $2.62 \pm 0.46$ & $11.72 \pm 1.76$ \\
\hline
\end{tabular}

* Results represent the mean fluorescence \pm 1 SEM.

$\dagger$ Expression of CRI was significantly greater at $37^{\circ} \mathrm{C}$ on vaginal cells than on adult PMNs ( $p=0.004$; corrected for multiple $t$ tests).

shown to be adequate for isolation of adult PMNs (see above). This was required in order to remove the lighter density neonatal erythrocytes. After isolation on Percoll density gradients, cells were incubated at 0 or $37^{\circ} \mathrm{C}$ for $1 \mathrm{~h}$ prior to staining. When the PMNs were maintained at $0^{\circ} \mathrm{C}$ after isolation, expression of both CR1 and CR3 were the same for neonatal and adult cells. When cells were warmed to $37^{\circ} \mathrm{C}$, receptor expression increased slightly as a result of the Percoll density gradient isolation procedure. This increase was of the same order of magnitude in both neonatal and adult cells with one exception. When isolated cells were warmed to $37^{\circ} \mathrm{C}$, expression of CR1 was greater ( $p=$ 0.004 ) on PMN from vaginally delivered infants than on adult PMNs. This was not found with cells from infants delivered by cesarean section without labor and may be due to factors associated with labor (see below).

The presence of nucleated red blood cells that remained in whole blood samples subjected to hypotonic lysis but not to density gradient isolation greatly increased the time required to determine the fluorescence of each sample. Since the effects of the isolation procedure per se did not affect the cord cells differently from the adult cells, subsequent studies were performed on isolated PMNs because of the relative ease in analyzing isolated cells on the FACS Analyzer.

$P M N$ receptor expression on adult versus neonatal PMNs after stimulation with $f-M L P$ or zymosan-activated serum. To determine whether complement receptor expression on neonatal PMNs stimulated with f-MLP was deficient when compared with adult cells, 10 experiments were conducted in which paired blood samples (one adult and one neonate) were isolated on density gradients of Percoll and incubated with concentrations of f-MLP ranging from $10^{-11}$ to $10^{-6} \mathrm{M}$. The cells were then stained with antibody to either CRI or CR3 and with FITC and then fluorescence determined. There was considerable individual to individual variability in the response of both neonatal and adult PMNs. Nevertheless, the mean increase in PMN expression of CR1 was similar in the two groups over the entire range of f-MLP concentrations examined (Fig. 1). In contrast, expression of CR3 was greater on adult than on neonatal PMNs. After incubation with $10^{-6} \mathrm{M}$ f-MLP, CR3 expression on PMNs from infants was only $71 \%$ of the mean value for receptor expression observed with adult PMNs $(p<0.001)$ (Fig. 2).

The response to zymosan-activated serum, used at a final concentration of 1:100, was also compared in PMNs obtained from eight adult and eight cord blood samples. While the major chemoattractant in zymosan-activated serum is generally consid-

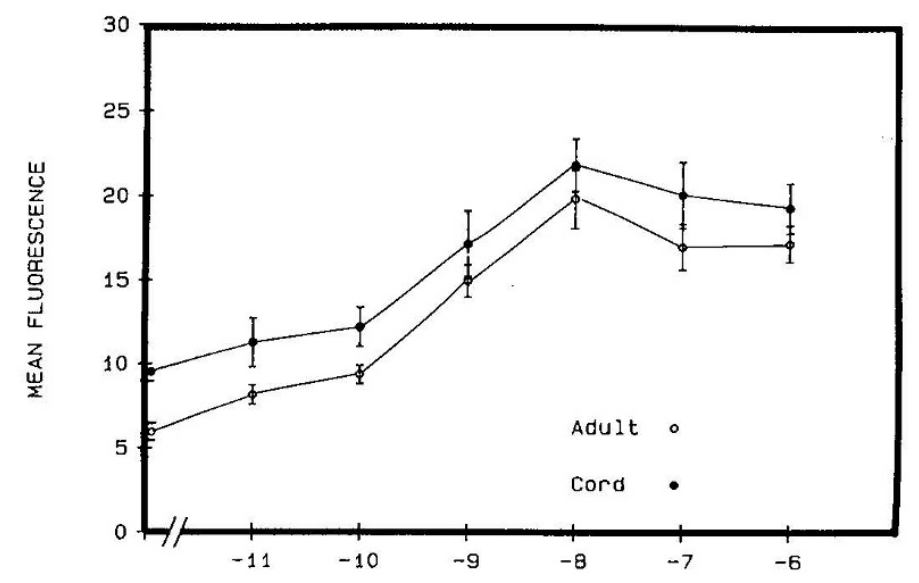

LOG MOLAA FMLP

Fig. 1. Effect of f-MLP concentration on $\mathrm{C} 3 \mathrm{~b}$ receptor expression on PMNs isolated from cord versus adult blood. Results are expressed as the overall mean \pm 1 SEM of the mean fluorescence for 10,000 cells for 10 samples in each of the two groups. There are no significant differences between the two groups.

ered to be C5a des Arg which has a unique receptor on the PMN, we cannot completely discount the possibility that the preparation contains small amounts of other chemoattractants that act on the same receptor as f-MLP. Mean values for expression of CR 1 were $16.99 \pm 1.32$ and $15.73 \pm 1.21$ for adult and cord PMNs, respectively, and did not differ significantly. However, zymosan-activated serum resulted in a significantly greater increase in CR3 expression on adult PMNs versus PMNs from infants. Mean CR3 expression was $24.06 \pm 1.20$ on adult PMNs compared with $18.78 \pm 0.70$ on cord PMNs $(p<0.01)$. Mean CR3 expression on cord PMNs was $78 \%$ of adult values.

Comparison of PMNs from adults versus neonates delivered by cesarean section. In order to determine whether type of delivery, e.g. vaginal or cesarean section, influenced receptor expression on neonatal PMNs, the adult and cord blood pairs described above were grouped according to method of delivery and the data reexamined. There were five experiments in which adult PMNs and PMNs from infants delivered by cesarean section without labor were compared. The increase in PMN expression 


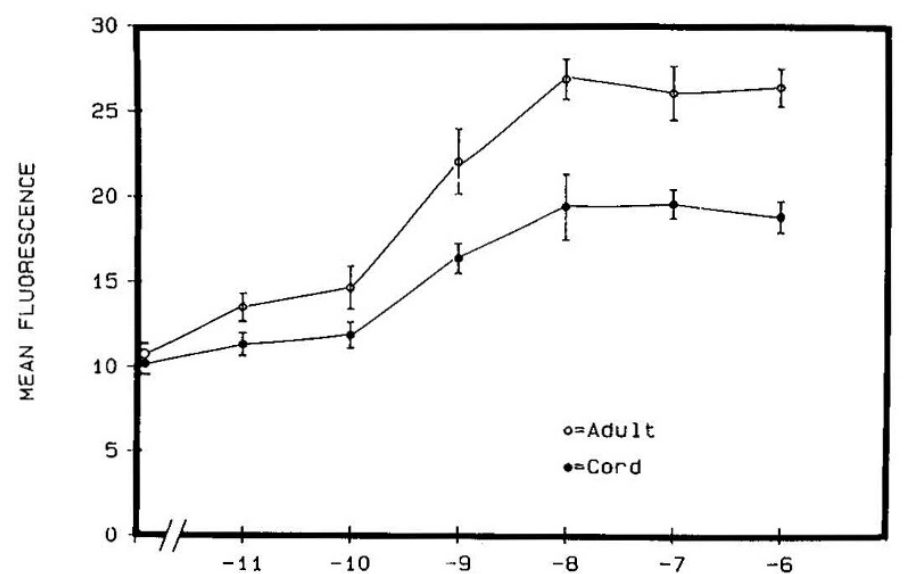

LOG MOLAR FMLP CONCENTRATION

Fig. 2. Effect of f-MLP concentration on C3bi receptor expression on PMNs isolated from cord versus adult blood. Results are expressed as the overall mean \pm 1 SEM of the mean fluorescence for 10,000 cells for 10 samples in each of the two groups. Expression of the C3bi receptor was significantly greater on adult cells than on cord PMNs at $10^{-6}$ to $10^{-10}$ M f-MLP $(p<0.05)$.

of CR1 did not differ in the adult and cesarean section infants over the entire range of f-MLP concentrations. At a concentration of $10^{-6} \mathrm{M}$ f-MLP, expression of CR3 on PMNs from cesarean section infants was $19.48 \pm 1.28$, only $76 \%$ of the value for receptor expression observed on adult PMNs, $25.68 \pm 1.31$ $(p=0.004)$. The response to zymosan-activated serum was also compared on PMNs obtained from five adult and five cord blood samples from infants delivered by cesarean section. Mean values for expression of CR1 were 17.20 \pm 2.12 and $15.64 \pm 1.73$ for adult and cord PMNs, respectively, and did not differ significantly. There was, however, a significantly smaller increase in CR3 expression on PMNs from infants delivered by cesarean section compared to adult PMNs. Mean CR3 expression on cesarean section PMNs was $75 \%$ of adult values, $18.50 \pm 0.88$ versus $24.53 \pm 1.74$, respectively $(p=0.0075)$ (Fig. 3 ).

Comparison of PMNs from adults and neonates delivered vaginally. Receptor expression in response to stimulation with $\mathrm{f}$ MLP was compared on PMNs from four adults and cord blood from four infants delivered vaginally. As was observed with PMNs from infants delivered by cesarean section, expression of CR1 was not different on adult versus cord PMNs. After stimulation with $10^{-6} \mathrm{M}$ f-MLP, mean fluorescence on adult PMNs was $17.60 \pm 1.91$ versus $20.72 \pm 1.71$ on cord PMNs. Maximal expression of CR3, however, was significantly greater on adult than on cord PMNs, $26.22 \pm 2.29$ versus $17.88 \pm 1.30$ for adult and cord PMNs, respectively $(p=0.0097)$. In response to zymosan-activated serum, expression of CRl was the same on adult $(16.64 \pm 1.14)$ and cord $(15.86 \pm 1.65)$ PMNs while expression of CR3 was significantly greater on adult than on cord PMNs. Values for mean fluorescence were $23.66 \pm 1.23$ for adult PMNs and $19.25 \pm 1.38$ for cord PMNs $(p=0.04)$ (Fig. 4).

Comparison of receptor expression on cord PMNs from neonates delivered vaginally versus by cesarean section. When PMNs were maintained at $0^{\circ} \mathrm{C}$, expression of $\mathrm{CR} 1$ and CR3 was virtually identical in cells from infants delivered by cesarean section compared with infants delivered vaginally. When cells were warmed to $37^{\circ} \mathrm{C}$, expression of both $\mathrm{CR} 1$ and $\mathrm{CR} 3$ were slightly, but not significantly, higher on PMNs from vaginally delivered infants compared with infants delivered by cesarean section. Expression of both CR1 and CR3 in response to f-MLP were the same on PMNs from infants delivered by cesarean

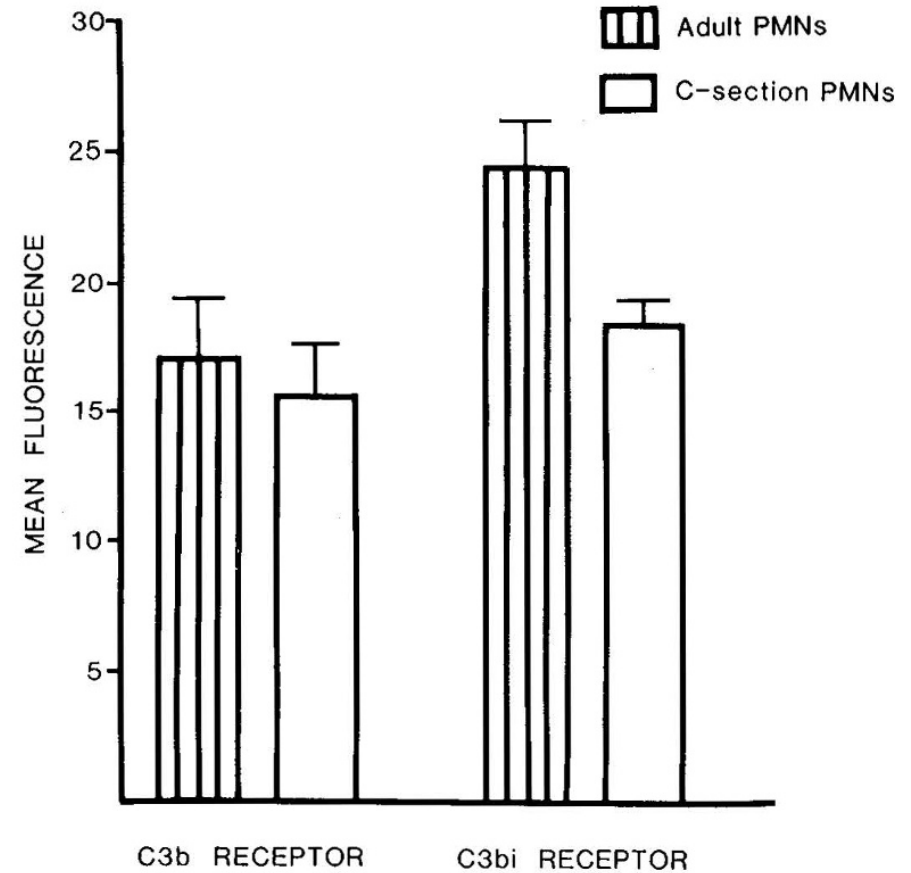

Fig. 3. Effect of stimulation with zymosan-activated serum on $\mathrm{C} 3 \mathrm{~b}$ and C3bi receptor expression on adult PMNs versus PMNs from cord blood of infants delivered by cesarean section without labor. Results are expressed as mean fluorescence \pm 1 SEM for eight cord and eight adult blood samples. Expression of the C3bi receptor was significantly greater on adult than on cesarean-section PMNs $(p=0.0075)$.

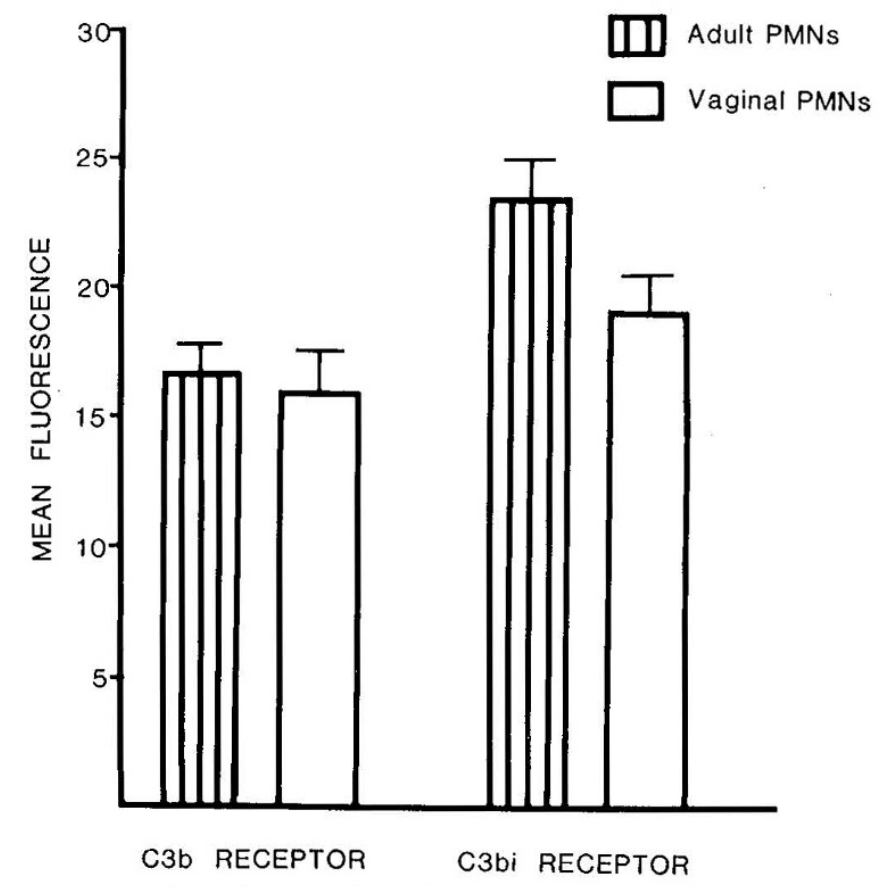

Fig. 4. Effect of stimulation with zymosan-activated serum on $\mathrm{C} 3 \mathrm{~b}$ and C3bi receptor expression on adult PMNs versus PMNs from cord blood of infants delivered vaginally. Results are expressed as mean fluorescence \pm 1 SEM for four adult and four cord blood samples. Expression of the $\mathrm{C} 3 \mathrm{bi}$ receptor was significantly greater on adult than on vaginal PMNs $(p=0.04)$.

section compared with infants delivered vaginally. The increase in the expression of either CR 1 or CR3 in response to zymosanactivated serum did not differ significantly between the two groups of infants. 


\section{DISCUSSION}

Activation of human neutrophils is accompanied by a rapid increase in the surface membrane expression of the receptors for $\mathrm{C} 3 \mathrm{~b}$ and $\mathrm{C} 3 \mathrm{bi}$, the major opsonically active fragments of the serum complement system (7-11). As CR3 is also important in neutrophil aggregation and in adherence of neutrophils to endothelium and other surfaces $(11,16-20)$, increased receptor expression is believed to be critically important for optimal margination, chemotaxis, and phagocytosis by these cells. The increase in receptor expression occurs rapidly and is the result of translocation from an intracellular pool rather than new synthesis $(7,10,21)$. In the present studies, we used monoclonal antibodies to CR1 and CR3 and flow cytometry to compare the ability of neonatal and adult PMNs to increase receptor expression in response to the stimuli f-MLP and zymosan-activated serum. The results indicate that although neonatal cells increase CR1 expression normally in response to these stimuli, their ability to increase CR 3 expression is deficient. The latter observation is in agreement with the preliminary observations of Anderson $e t$ al. (22).

Serum factors associated with pregnancy, labor, and/or delivery apparently did not influence the expression of these receptors per se because the levels of expression of both CR 1 and CR 3 in cells maintained at $0^{\circ} \mathrm{C}$ was the same on adult and neonatal cells. Berger et al. (7) have shown that at this temperature, receptor expression remains stable at whatever level was achieved before the cells were cooled. Previous studies indicated that when neutrophils are isolated by procedures involving centrifugation, a spontaneous increase in receptor expression may occur when the cells are subsequently warmed to $37^{\circ} \mathrm{C}$, even in the absence of additional stimuli $(7,8)$. The mechanism of this effect is unknown but may involve release of intracellular calcium stores (23) and/or other membrane perturbations caused by the physical forces encountered by cells during purification. When compared with adult values, isolated PMNs from cord blood of infants born by vaginal delivery after labor had significantly greater spontaneous increases in CR 1 expression. This difference was not found with infants delivered by cesarean section without labor. These results suggest that during labor and vaginal delivery the PMNs may encounter physical forces or perturbations similar to those that cause some degree of spontaneous activation following purification procedures.

Labor has been reported by other investigators to alter the function of neonatal PMNs. Frazier et al. (24) found that oxidative metabolism was significantly decreased in PMNs from infants delivered vaginally or by cesarean section after labor compared with PMNs from adults or infants delivered by cesarean section without labor. Differential counts were similar in infants delivered with and without labor suggesting that increased numbers of immature PMNs were not responsible for the observed differences. Also pertinent was their observation that the oxidative metabolism of PMNs obtained from women immediately after delivery, either vaginal or cesarean section, was similar to values obtained from normal adults. Serum levels of corticosteroids, fatty acids, and prostaglandins have been reported to differ in infants delivered with and without labor (25-27). It is possible that these or other chemical substances or physical factors per se might play a role in the alteration of PMN function.

In both adult and cord blood PMNs, exposure to the chemoattractants f-MLP and zymosan-activated serum resulted in significant increases in expression of CR 1 and CR 3 above baseline levels. The expression of CR1 in response to stimulation with either f-MLP or zymosan-activated serum did not appear to be deficient in neonates delivered either by cesarean section or vaginally when compared with adult control values. In contrast, CR3 expression did not increase to the same extent in neonatal PMNs as in adult PMNs following stimulation with either $\mathrm{f}-$ MLP or zymosan-activated serum. Total CR3 expression on isolated PMNs from infants delivered by cesarean section was
$76 \%$ of adult values after stimulation with f-MLP and $75 \%$ of adult values after stimulation with zymosan-activated serum. This difference was also found when PMNs not subjected to Percoll density gradient isolation were stimulated with f-MLP. In fact in experiments performed using unfractionated whole blood, maximal CR3 expression on neonatal cells was only $62 \%$ of the adult values. Expression of CR 1 on whole blood PMNs was the same for adults and neonates. These results indicate that the differences we observed are not due to different susceptibility of neonatal and adult cells to the effects of the Percoll density gradient purification procedure.

Extensive studies of children and young adults with congenital phagocyte defects and recurrent infections have demonstrated an association between CR3 and PMN adhesion. Deficiency of this receptor and related proteins is accompanied by defective adherence, spreading, and chemotaxis. Phagocytosis is impaired and the respiratory burst in response to $\mathrm{C} 3 \mathrm{~b}$ and $\mathrm{C} 3 \mathrm{bi}$-coated particles is diminished $(16-20)$. The defect in CR3 expression observed in our studies may explain the observations by Anderson et al. (2) that neonatal PMNs are abnormal with respect to adherence. Impaired expression of CR 3 could be due to a relative decrease in the total number of receptors or to an impaired ability to translocate this receptor from its intracellular pool to the surface membrane. Our results are not likely to be due to altered sensitivity of the neonatal cells to f-MLP, however, since there was no difference between adult and neonatal PMNs with respect to CR1 expression, the peak responses of neonatal and adult cells occurred at the same f-MLP concentration, and a similar deficiency in CR3 response was observed with zymosanactivated serum as the stimulus.

We are presently pursuing further studies aimed at elucidating the cause of the decreased CR3 expression in neonatal cells. Although we have not performed functional assays in this study, the correlation between the decreased CR 3 expression we observed and the previously reported defects in adherence and phagocytosis are striking $(1,2,5)$. The precise significance of this quantitative deficiency of CR3 expression remains to be determined. However, it seems likely that the deficiency documented herein contributes to the functional impairment of neonatal PMNs and to the increased susceptibility of the neonate to infection, particularly with bacteria such as group B streptococcus which require opsonization for optimal phagocytosis.

\section{REFERENCES}

1. Wilson CB 1986 Immunologic basis for increased susceptibility of the neonate to infection. J Pediatr 108:1-12

2. Anderson D, Hughes B, Smith CW 1981 Abnormal motility of neonatal polymorphonuclear leukocytes. J Clin Invest 68:863-874

3. Sacchi F, Hill HR 1984 Defective membrane potential changes in neutrophils from human neonates. J Exp Med 160:1247-1252

4. Strauss RG, Snyder EL 1983 Activation and activity of the superoxidegenerating system of neutrophils from human infants. Pediatr Res 17:662664

5. Matoth Y 1952 Phagocytic and ameboid activities of the leukocytes in the newborn infant. Pediatrics 9:748-755

6. Miller ME 1969 Phagocytosis in the newborn infant: humoral and cellular factors. J Pediatr 74:255-259

7. Berger M, O'Shea J, Cross AS, Folks TM, Chused EJ, Brown EJ, Frank MM 1984 Human neutrophils increase expression of C3bi as well as C $3 b$ receptors upon activation. J Clin Invest 74:1566-1571

8. Fearon DT, Collins LA 1983 Increased expression of C3b receptors on polymorphonuclear leukocytes induced by chemotactic factors and by purification procedures. J Immunol 130:370-379

9. Todd RF, Arnaout MA, Rosin RE, Crowley CA, Peters WA, Babior BM 1984 Subcellular localization of the large subunit of Mol, a surface glycoprotein associated with neutrophil adhesion. J Clin Invest 74:1280-1290

10. O'Shea J, Brown EJ, Seligman BE, Metcalf JA, Frank MM, Gallin JI 1985 Evidence for distinct intracellular pools of receptors for C3b and C3bi in human neutrophils. J Immunol 134:2580-2587

11. Arnaout MA, Hakim RH, Todd RF, Dana N, Colten HR 1985 Increased expression of an adhesion-promoting surface glycoprotein in the granulocytopenia of hemodialysis. N Engl J Med 312:457-462

12. Harbeck RJ, Hoffman AA, Redecker S, Biundo T, Kurnick J 1982 The isolation and functional activity of polymorphonuclear leukocytes and lymphocytes separated from whole blood on a single Percoll density gradient. 
Clin Immunol Immunopathol 23:682-690

13. Craddock PR, Fehr J, Dalmasso A, Brigham K, Jacob H 1977 Hemodialysis leukopenia: Pulmonary vascular leukostasis resulting from complemen activation by dialyzer cellophane membranes. J Clin Invest 59:879-888

14. Beller DI, Springer TA, Schreiber RD 1982 Anti-Mac I selectively inhibits the mouse and human type three complement receptor. J Exp Med 156:10001009

15. Cupples LA, Heeren T, Schatzkin A, Colton T 1984 Multiple testing of hypotheses in comparing two groups. Ann Intern Med 100:122-129

16. Gallin J 1985 Leukocyte adherence-related glycoproteins LFA-1, M01, and p150,95: a new group of monoclonal antibodies, a new disease, and a possible opportunity to understand the molecular basis of leukocyte adherence. $\mathbf{J}$ Infect Dis 152:661-664

17. Anderson DC, Schmalstieg FC, Finegold MJ, Hughes BJ, Rothlein R, Miller LJ, Kohl S, Tosi MF, Jacobs RL, Waldrop TC, Goldman AS, Shearer WT, Springer TA 1985 The severe and moderate phenotypes of heritable Mac-1, LFA-1 deficiency: their quantitative definition and relation to leukocyte dysfunction and clinical features. J Infect Dis 152:668-669

18. Anderson DC, Schmalstieg FC, Arnaout MA, Kohl S, Tosi M, Buffone GJ, Hughes BJ, Brinkley BR, Dickey WD, Abramson JS, Springer T, Boxer LA Hollers JM, Smith CW 1984 Abnormalities of polymorphonuclear leukocyte function associated with a heritable deficiency of high molecular weigh surface glycoproteins (GP138): common relationship to diminished cell adherence. J Clin Invest 74:536-551

19. Crowley CA, Curnutte JT, Rosin RE, Andre-Schwartz J, Gallin JI, Klempner
M, Snyderman R, Southwick FS, Stossel TP, Babior BM 1980 An inherited abnormality of neutrophil adhesion. Its genetic transmission and its association with a missing protein. N Engl J Med 302:1163-1168

20. Bowen TJ, Ochs HD, Altman LC, 1982 Severe recurrent bacterial infection associated with defective adherence and chemotaxis in two patients with neutrophils deficient in a cell-associated glycoprotein. J Pediatr 101:932-940

21. Berger M, Cross AS 1984 Lymphoblastoid cell supernatants increase expression of $\mathrm{C} 3 \mathrm{~b}$ receptors on human polymorphonuclear leukocytes: direct binding studies with ${ }^{125}$ I-C $3 b$. Immunology 51:431-440

22. Anderson DC, Freeman KB, Hughes BJ, Buffone GJ 1985 Secretory determinants of impaired adherence and motility of neonatal PMNs. Pediatr Res 19:257A(abstr)

23. Berger M, Birx DL, Wetzler EM, O'Shea JJ, Brown EJ, Cross AS 1985 Calcium requirements for increased complement receptor expression during neutrophil activation. J Immunol 135:1342-1348

24. Frazier JP, Cleary TG, Pickering LK, Kohl S, Ross PJ 1982 Leukocyte function in healthy neonates following vaginal and cesarean section deliveries. $J$ Pediatr 101:269-272

25. Cawson MJ, Anderson ABM, Turnball AC 1974 Cortisol, cortisone, and 11deoxycortisol levels in human umbilical and maternal plasma in relation to the onset of labor. J Obstet Gynaecol Br Commonwealth 81:737-745

26. Murphy BEP, 1973 Does the human fetal adrenal play a role in parturition? Am J Obstet Gynecol 115:521-5

27. Karim SMM and Devlin J 1967 Prostaglandin content of amniotic fluid during pregnancy and labor. J Obstet Gynaecol Br Commonwealth 74:230-234 